\title{
Aspects of natural history in a sand boa, Eryx muelleri (Erycidae) from arid savannahs in Burkina Faso, Togo, and Nigeria (West Africa)
}

\author{
Leonardo Vignolia, Gabriel Hoinsoudé Segniagbeto ${ }^{b}$, Edem A. Eniang ${ }^{c}$, \\ Emmanuel Hema ${ }^{d}$, Fabio Petrozzi ${ }^{\mathrm{e}, \mathrm{f}}$, Godfrey C. Akani ${ }^{\mathrm{e}}$ and Luca Luisellie,
}

aDipartimento di Scienze, Università Roma Tre, Roma, Italia; 'Département de Zoologie et Biologie animale, Faculté des Sciences, Université de Lomé, Lomé, Togo; 'Department of Forestry and Wildlife, University of Uyo, Uyo, Nigeria; dUniversité de Ouagadougou/CUPD, Laboratoire de Biologie et Ecologie Animales, 09 B.P. 848; and Groupe des Expert en Gestion des Elephant et de la Biodiversite de l'Afrique de

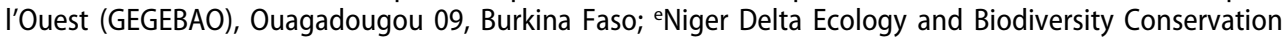
Unit, Department of Applied and Environmental Biology, Rivers State University of Science and Technology, Port Harcourt, Nigeria; ${ }^{\mathrm{f}}$ Ccologia Applicata Italia s.r.l., Roma, Italia; ${ }^{9}$ Centre of Environmental Studies Demetra s.r.l., Roma, Italia

\begin{abstract}
The ecology of West African arid savannah snakes is still poorly known, especially in regard to the fossorial species. Here, field data on distribution, morphometrics, habitat use and diet are reported for the sand boa Eryx muelleri (Erycidae) from three different countries, i.e. Burkina Faso, Togo and Nigeria. This snake was observed in 21 distinct localities, and a total of 39 individuals was recorded. The species is likely fairly common and locally abundant. Mean body length of snakes was similar among countries and between sexes, but males had proportionately longer tails than females. Body length was significantly positively correlated with both tail length and head length. Adult sex ratio was close to parity. Most of the specimens were found in well-vegetated spots with low percentage of bare soil. There were apparently both ontogenetic and intersexual dietary variations: (1) a single analysed juvenile fed upon a small-sized lizard, whereas adults fed considerably upon young rodents; and (2) females fed exclusively upon young rodents and males upon both lizards and young rodents. In conservation terms, the species is actively exported from Togo for the pet trade, and additional individuals may also be illegally collected in other countries.
\end{abstract}

\section{ARTICLE HISTORY}

Received 5 March 2015

Accepted 10 August 2015

Online 14 September 2015

\section{KEYWORDS}

Boas; arid savannahs; natural history; body size; habitat use; diet

\section{Introduction}

The ecology and natural history of Sahel reptiles are poorly known, despite there being a considerable amount of data on the distribution of the various species (e.g., Trape et al. 2012). The ecology of subterranean snakes is also poorly investigated, especially with regard to African tropical snakes (e.g., Angelici et al. 2000; Luiselli et al. 2002; Akani et al. 2008; Petrozzi et al. 2014). In particular, we are not aware of any specific ecological study 

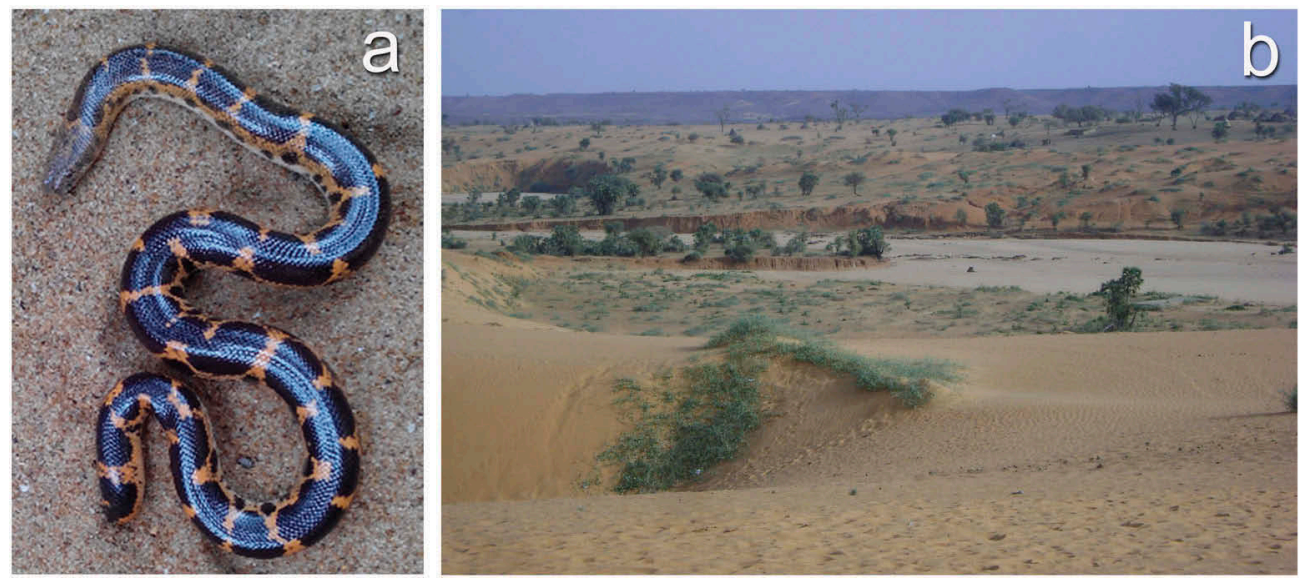

Figure 1. (a) Eryx muelleri from Kebbe, north-western Nigeria (Photo: Luca Luiselli); (b) dry savannah habitat of Eryx muelleri in northern Burkina Faso (Photo: Emmanuel Hema).

on the subterranean snakes of the arid savannas (northern Sudanian and Sahelian region), including the erycid sand boas of the genus Eryx. Indeed, the natural history of these sand boas is known only through fragmentary and anecdotal data (Villiers 1950; Andrijczuk 2006; Chirio \& LeBreton 2007; Chirio 2009). Here, we report ecological data on Eryx muelleri (Figure 1a), a small-sized (less than $80 \mathrm{~cm}$ long) sand boa with a wide distribution in Sahel (Trape \& Mane 2006; Chippaux 2007). More specifically, we report data on the local distribution, morphometrics, habitat use, and feeding of free-ranging individuals from several populations from Burkina Faso, Togo, and Nigeria (West Africa). Although based on scattered and relatively small sample sizes, the present study represents the most detailed article reporting quantitative field data on the ecology of E. muelleri.

\section{Materials and methods}

\section{Study species}

Species of Erycidae (sensu Pyron et al. 2014) are found in Europe, Asia, and Africa. Old World species, which were split between two genera (Eryx and Gongylophis) by Tokar (1995), are now considered to belong to the genus Eryx (Reynolds et al. 2014).

Eryx muelleri is a monotypic species showing no geographical variation in morphology, and is distributed from Senegal to the eastern Sudan (Tokar 1995). This species is reported to inhabit arid savannahs and semi-deserts, but avoids loose sand (Chirio 2009). There are no data on its field biology except a few fragmentary notes (Sorensen 1987).

\section{Study areas and field methods}

Data were collected from several localities of arid savannahs (Figure 1b), in three different West African countries, i.e. Burkina Faso, Togo, and Nigeria (Figure 2). All areas are characterized by an arid-tropical climate, with a long dry season occurring from October to the end of May and a much shorter wet season from June to September. 


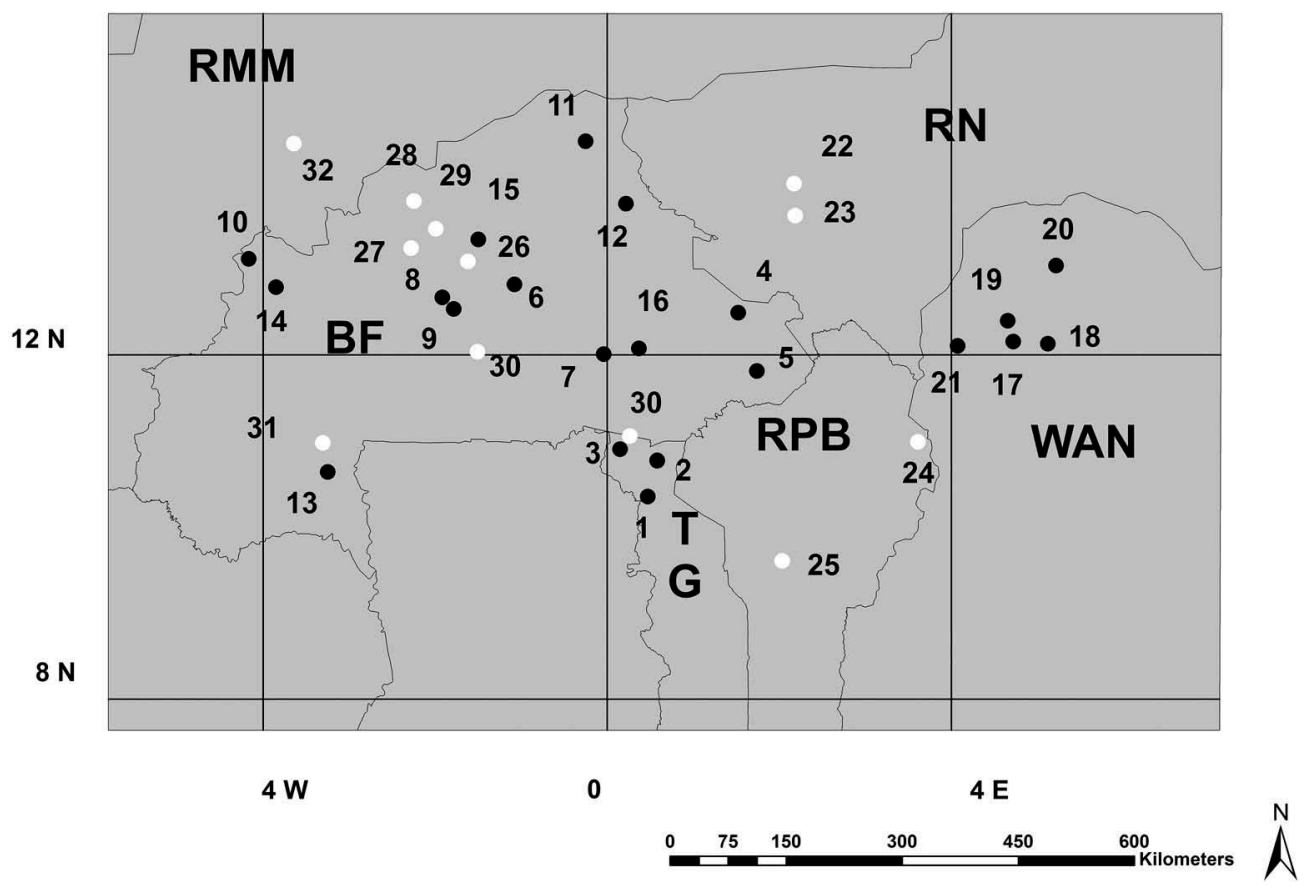

Figure 2. Locality records of Eryx muelleri. Black dots indicate original localities from this study; white dots indicate historical records <http://portal.vertnet.org/search?q=Eryx+muelleri $>$. Symbols: $\mathrm{BF}=$ Burkina Faso; RMM = Mali; RPB = Benin; $\mathrm{TG}=$ Togo; $\mathrm{WAN}=$ Nigeria; $\mathrm{RN}=$ Niger. Numbers refer to capture localities as given in Appendix 1.

Voucher specimens were examined for morphometric measurements and other biological data (see below). The following vouchers were analysed: MRAC 29651, 29663; MRCA 29472 and one specimen examined in the Reptiles Trade farms of Mare in Lomé, Togo; CNRST (Ouagadougou): HV 378, HV 2592, HV 2727, HV 3147, HV 4342, HV 357, HV 4288, HV 3002, HV 4119, HV 1029, HV 3643, HV 1406, HV 2884. From each voucher, the snout-vent length (SVL, precision $2 \mathrm{~mm}$ ), tail length (tL), and head length $(\mathrm{HL})$ were measured, and their sex was also determined. Vouchers were also dissected to obtain any ingested food.

In addition, specifically dedicated field surveys were also performed in order to obtain data on free-ranging individuals. Field data were recorded during standardized longterm studies on Togolese reptiles (e.g. Segniagbeto et al. 2011) and, as opportunistic observations, during several short-term surveys in Burkina Faso and northern Nigeria (years 2013-2014). These opportunistic observations were made with the help of local people who were expert in locating these elusive snakes. Because of the heterogeneous field protocol and the problematic logistics, the field effort performed in each locality and in each habitat type was not quantified. Snakes were searched for under all weather conditions during the day and at night, although a stronger field effort was conducted between 0800 and 1800 hours. Several transects were walked in each study locality. Transects were laid in arid savannah habitats, exploring both vegetated and bare soil patches. When a snake was encountered in the field, the percentage of bare soil around the site of capture was recorded. The percentage of bare soil was approximated by 
estimating by eye the amount of bare soil in five randomly placed spots of $1 \mathrm{~m} \times 1 \mathrm{~m}$ surface, within $10 \mathrm{~m}$ radius from the precise site of capture of the individual. The same procedure was adopted when a snake was located under a cover object (a stone or a piece of wood) or inside a gallery (rodent-made holes on ground or other animal-made tunnels in the sandy soil). Snakes were captured by hand. Each caught individual was sexed, measured for snout-vent length ( $S V L$, precision $2 \mathrm{~mm}$ ) and tail length ( $\mathrm{tL}$ ), and individually marked by ventral scale clipping for future identification. Snakes were also palpated in the abdomen for any food item, and eventually forced to regurgitate the ingested bolus by abdominal squeezing (Luiselli \& Amori in press). Prey items were recovered only once from each captured individual, thus avoiding pseudoreplication.

In order to guide the surveys, farmers and hunters were interviewed to add qualitative information on distribution and perceived abundance of the study species at the local level. Obviously, the information obtained from interviewees was not used for any analysis in this paper.

Parametric tests were performed when the variables were normally distributed; otherwise, nonparametric tests were used (e.g., $X^{2}$ test for habitat analyses). For all analyses, the individual identity of each snake was considered, i.e. pseudoreplication was avoided. A two-way ANOVA by sex and by country, with snake body size (SVL, mm) as a dependent variable, was performed in order to explore the intersexual and interregional differences in this species' length. Intersexual differences in tail length and in head length were assessed by Student $t$-test. In the text, means are followed by \pm 1 Standard Deviation. Data were processed by Statistica version 8.0, with all tests being two-tailed and alpha set at 5\%.

\section{Results and discussion}

\section{Distribution}

Overall, we recorded 39 free-ranging individuals of Eryx muelleri from 21 distinct localities: 13 from Burkina Faso, five from Nigeria, and three from Togo (Figure 2). The species is likely fairly common and locally abundant, as it is well known to natives all over the study region, and reported to be among the commonest species by all interviewees.

All individuals were observed in dry savannahs situated in the Northern Sudanian ecological zone. However, one presence locality (Djibo, Burkina Faso) was situated in the Sahelian region, at the transition between desert and arid savannah. All the localities given here were situated inside the known geographic range of the species (Figure 2; Appendix 1; see also map in Chippaux 2007 for comparison). Some of these localities were already available in the literature (e.g., the three Togo localities were already reported by Segniagbeto et al. 2011).

\section{Morphometrics, habitat use and feeding}

Mean SVL of snakes did not differ significantly among the three countries (Table 1) and between sexes (Table 2). However, females ( $x=47.6 \pm 9.6 \mathrm{~cm} \mathrm{SVL}, n=19$ ) were larger than males $(x=41.3 \pm 10.2 \mathrm{~cm} \mathrm{SVL}, n=20)$, and the intersexual difference in SVL fell short of statistical significance (Table 2). Once the samples from all the study sites were 
Table 1. Variation of body size (SVL, cm) of Eryx muelleri across countries. For the statistical significance, see Table 2.

\begin{tabular}{lrrr}
\hline & Mean & $N$ & Std. Deviation \\
\hline Burkina & 42.97 & 13 & 10.92 \\
Nigeria & 44.85 & 21 & 10.63 \\
Togo & 5 & 8.08 \\
Total & 45.90 & 39 & 10.25 \\
\hline
\end{tabular}

Table 2. Test of between-subjects effects for the variation of body length of Eryx muelleri (SVL, $\mathrm{mm}$ ) in relation to sex and to country of origin.

\begin{tabular}{lrrrrr}
\hline \multicolumn{5}{l}{ Dependent variable: SVL $(\mathrm{cm})$} & \multicolumn{5}{c}{} \\
\hline Source & Type III sum of squares & Df & Mean square & \multicolumn{1}{c}{$F$} & $P$ \\
\hline Corrected Model & 407.343 & 3 & 135.781 & 1.324 & 0.282 \\
Intercept & $10,119.701$ & 1 & $10,119.701$ & 98.700 & 0.000 \\
Country & 365.430 & 1 & 365.430 & 3.564 & 0.067 \\
Sex & 29.028 & 2 & 14.514 & 0.142 & 0.868 \\
Error & 3588.543 & 35 & 102.530 & & \\
Total & $80,730.701$ & 39 & & & \\
Corrected Total & 3995.885 & 38 & & & \\
\hline
\end{tabular}

pooled, SVL was significantly positively correlated with both tail length ( $r=0.831, n=39$, $P<0.0001$; Figure 3a) and head length $(r=0.835, n=39, P<0.0001$; Figure 3b). Once body size is taken into account, males had significantly longer tails than females $(t=2.119, \mathrm{df}=37, P=0.041)$, whereas there were no intersexual differences in terms of head length ( $t=1.27$, $\mathrm{df}=37, P=0.212$ ).

Adult sex ratio of free-ranging individuals (males: females $=0.7: 1, n=34$ ) was even $\left(X^{2}=0.533, \mathrm{df}=1, P=0.465\right)$.

Microhabitat data were collected from 39 individuals (Figure 4). The majority of the individuals, either males, females or juveniles, were found in well-vegetated spots with low percentage of bare soil (Figure 4). Observed habitat use by snakes was significantly uneven $\left(X^{2}=14.9, \mathrm{df}=4, P<0.005\right)$.

Diet data were recorded from a total of 13 out of 39 examined individuals. A few individuals contained more than one prey item, so we collected 17 prey items in total: three Trachylepis quinquetaeniata (two from males, one from juveniles), one Agama sp. (from a male), and 13 immature rodents (six from males, seven from females). Thus, although a small sample size especially for juvenile individuals, it appeared that there were both ontogenetic and intersexual dietary variations:

(1) the single analysed juvenile fed upon a small-sized lizard, whereas adults fed substantially upon young rodents;

(2) females fed exclusively upon young rodents and males upon both lizards and young rodents.

Since snakes are gape-limited predators that consume their prey whole, the head size sets an upper limit to a snake's maximum ingestible prey size (e.g. Forsman 1991). Thus, we suggest that the above-mentioned ontogenetic dietary shifts (from ectotherm to endotherm food items) presumably reflect the need of larger mouth gape to prey upon small mammals compared with small-medium lizards (Rodriguez-Robles et al. 1999). Head size of juvenile Eryx muelleri (SVL range: $20-30 \mathrm{~cm}$ ) ranged $0.8-2.0 \mathrm{~cm}$ in length, thus being likely too small for eating adult rodents. Indeed, the observed ontogenetic 
a)

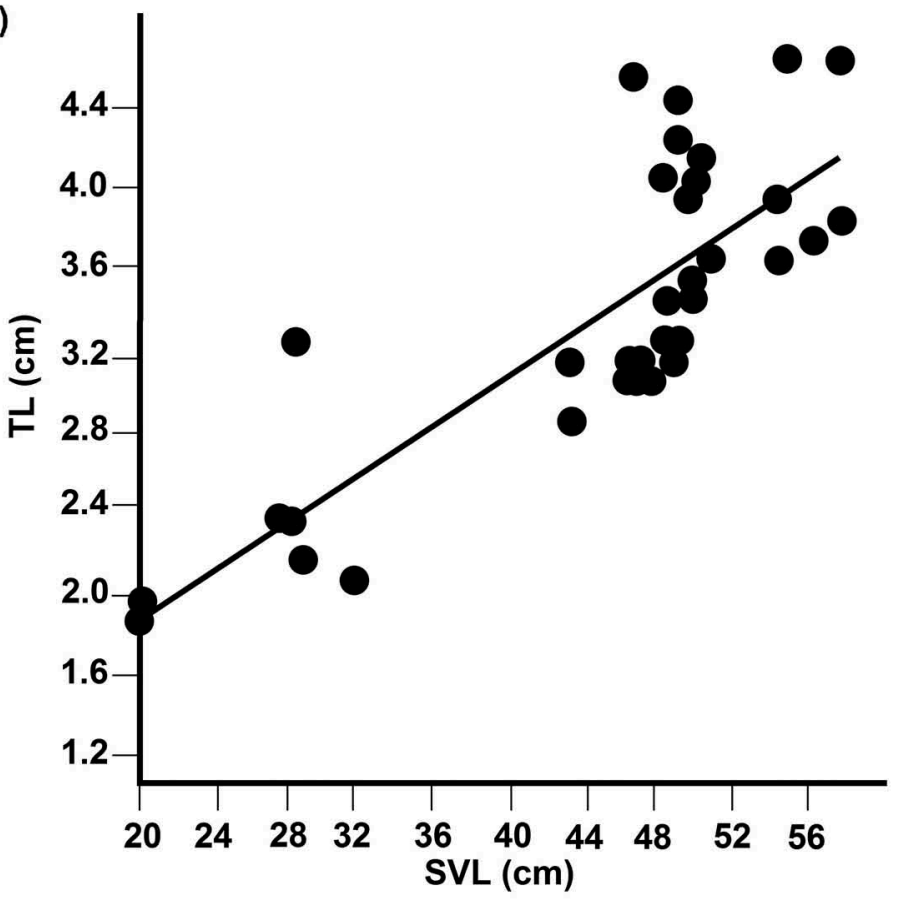

b)

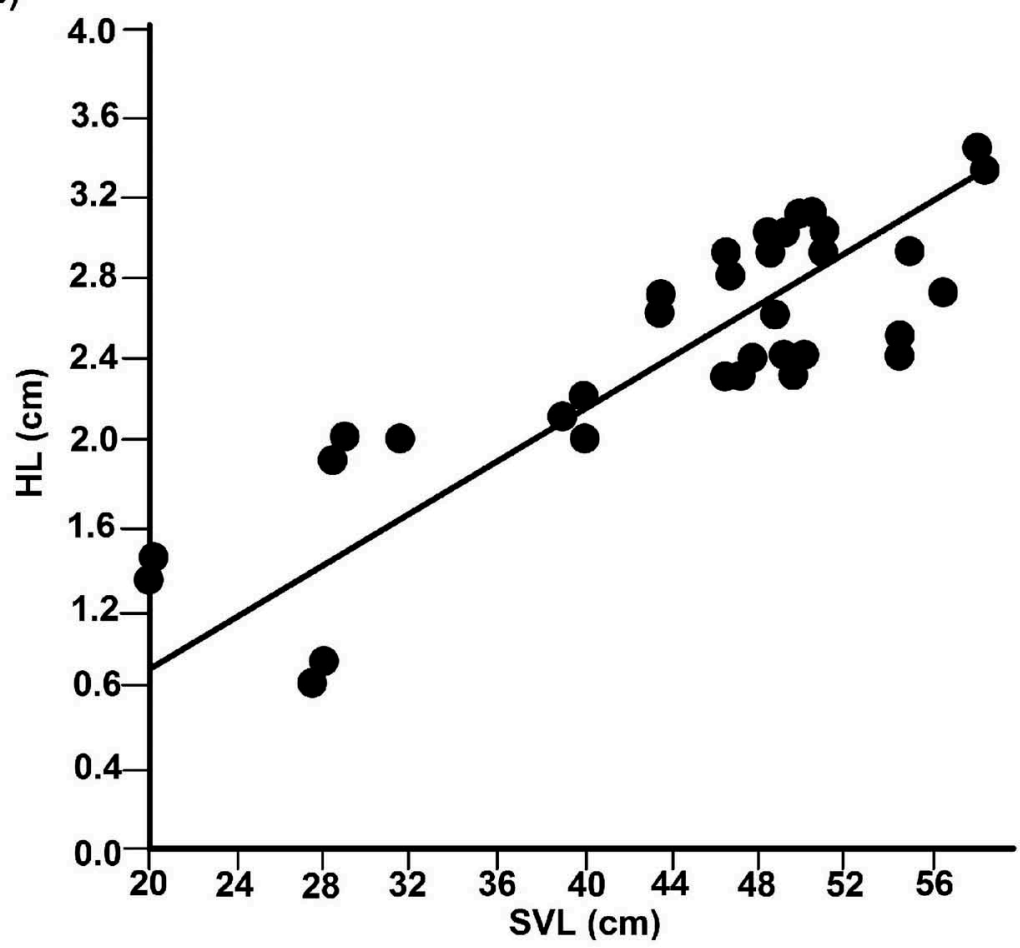

Figure 3. Relationships between (a) Snout-Vent-Length (SLV) and Tail Length (TL), and between (b) SVL and Head Length (HL) in Eryx muelleri. Specimens from Togo, Burkina Faso and Nigeria were pooled. 


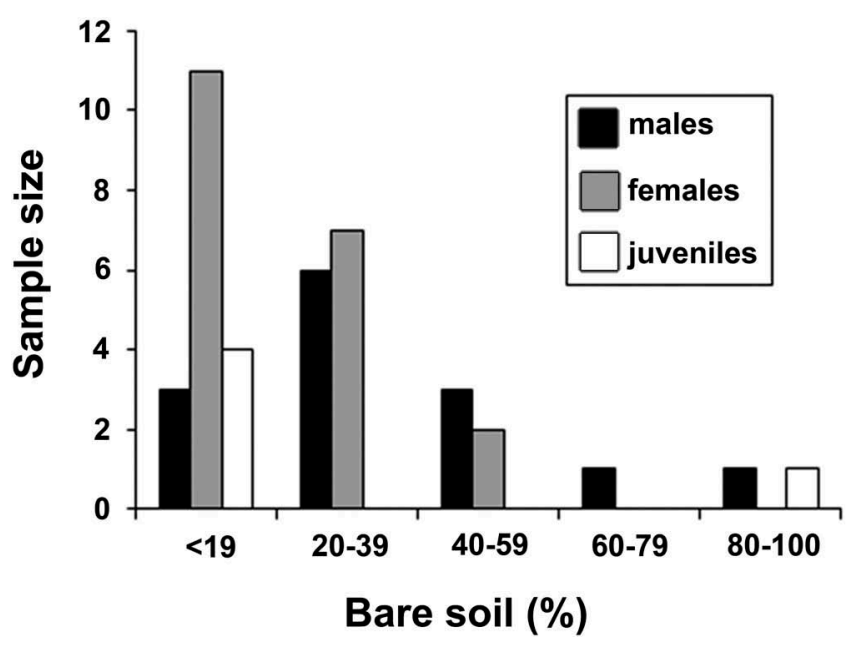

Figure 4. Microhabitat use by Eryx muelleri. Sample size would indicate the number of captured specimens.

diet variations are widespread among other sand boa species, even of different families (e.g. Charina bottae; Rodriguez-Robles et al. 1999), as well as other snake groups (boids: Henderson et al. 1987; Henderson 1993; pythons: Slip \& Shine 1988; Shine \& Slip 1990; vipers: Fitch 1960; colubrids: Greene 1989; Luiselli et al. 1996, 1997; elapids: Shine 1980). There is theoretical and empirical evidence for well-established connections between diet and reproductive performance (Maklakov et al. 2008) in support of the observed divergence in dietary habits between the sexes. Indeed, sexes are likely under selection for different dietary preference and resource utilization that maximize their sex-specific fitness (Hunt et al. 2004). For example, one sex may feed more frequently than the other, or take different kinds of prey (e.g. Shine 1989). Since Eryx muelleri apparently does not show intersexual size dimorphism (Tokar 1995; this paper), the observed sex divergence should be caused by an ecological shift between the sexes that is independent of body size. Our findings resemble those of Luiselli et al. $(1996,1997)$ who found that in colubrid species with no evident sexual size dimorphism, the adult females diverged in dietary habits from males by taking larger prey. The observed intersexual dietary spectrum could be the result of different foraging modes, as sand boa species can use both wideforaging and ambush tactics in hunting prey (Rodriguez-Robles et al. 1999). As suggested by Luiselli et al. (1996) for Coronella austriaca, during the mating period, females may use ambush predation, a strategy that may be unsuited to adult males because of their need to engage in prolonged mate-searching movements. Whatever its cause, the ontogenetic dietary shift in females to take larger prey may significantly enhance energy intake, and thus allow larger females to reproduce more frequently, with larger litters of larger offspring (Luiselli et al. 1996).

\section{Conservation remarks}

This species is currently exploited from Togo and probably also from the rest of its distribution for the pet trade. For instance, inspection of the CITES database revealed 
that, from 2007 to 2012, 571 specimens were exported from Togo according to the data available in the website of WCMC-PNUE (http://trade.cites.org/) of 23 February 2015. Together with other West African reptile species with Sahelian distribution (Centrochelys sulcata and Uromastyx geyri), individuals of Eryx muelleri are constantly present in the pet market in Togo (Segniagbeto, Luiselli and Petrozzi, unpublished data). It is sure that individuals of these (and possibly of other species) pass from one country to another in the sub-region, due to the hyper-porous borders and weak border controls facilitating illegal trafficking. Although regulated officially by quotas, the illegal trans-country trade remains a concern as the actual amount of traded animals cannot be controlled. Nowadays, all the exported individuals are labelled as W (wild) in the CITES database, and the potential impact of the exploitation of Eryx muelleri wild populations is not known. During the present study, several interviewed hunters/farmers claimed that Eryx muelleri is still widespread and common, especially in Burkina Faso. However, if the trade of these snakes continues, and if the effect of this trade is pooled with the effects of habitat degradation and climate change in this sub-region of West Africa, it is possible that the wild population of this species will decline. However, at present, the pet trade does not seem to represent an immediate threat to the survival of the study species. Anyway, widespread snake declines have already been reported for West Africa (Reading et al. 2010).

\section{Acknowledgements}

The Directorship of the Centre National de Recherche Scientifique et Technique (CNRST), Ouagadougou, is thanked for having allowed us to examine and analyze the large snake collection under their care. Dr Marco Zuffi and two anonymous referees considerably improved the submitted draft.

\section{Disclosure statement}

No potential conflict of interest was reported by the authors.

\section{Funding}

This study was supported by the Mohamed Bin Zayed Species Conservation Fund.

\section{References}

Akani GC, Luiselli L, Eniang EA, Amuzie CC, Ebere N. 2008. Aspects of the ecology of the spotted blindsnake, Typhlops punctatus punctatus in Port-Harcourt, Nigeria. Afr J Ecol. 46:533-539.

Andrijczuk C. 2006. Das Verteidigungsverhalten der Sandboa Gongylophis muelleri (Boulenger 1892), mit einigen Anmerkungen zur Taxonomie. Elaphe. 14:52-56.

Angelici FM, Inyang MA, Effah C, Luiselli L. 2000. Analysis of activity patterns and habitat use of radiotracked African burrowing pythons, Calabaria reinhardtii. Isr J Zool. 46:131-141.

Chippaux J-P. 2007. Les serpents d'Afrique occidentale et central. Paris: IRD Editions.

Chirio L. 2009. Inventaire des reptiles de la région de la Réserve de Biosphère Transfrontalière du W (Niger/Bénin/Burkina Faso: afrique de l'Ouest). Bull Soc Hérp. 132:13-41.

Chirio L, LeBreton M. 2007. Atlas des Reptiles du Cameroun. Paris: IRD Editions. 
Fitch HS. 1960. Autecology of the copperhead. Univ Kansas Publ Mus Nat Hist. 13:85-288.

Forsman A. 1991. Adaptive radiation in head size in Vipera berus L. populations. Biol J Linn Soc. 43:281-296.

Greene HW. 1989. Ecological, evolutionary, and conservation implications of feeding biology in Old World cat snakes, genus Boiga (Colubridae). Proc Calif Acad Sci. 46:193-207.

Henderson RW. 1993. Foraging and diet in West Indian Corallus enydris (Serpentes: Boidae). J Herpetol. 27:24-28.

Henderson RW, Noeske-Hallin TA, Ottenwalder JA, Schwartz A. 1987. On the diet of the boa Epicrates striatus on Hispaniola, with notes on E. fordi and E. gracilis. Amphibia-Reptilia. 8:251-258.

Hunt J, Brooks R, Jennions MD, Smith MJ, Bentsen CL, Bussiere LF. 2004. High-quality male field crickets invest heavily in sexual display but die young. Nature. 432:1024-1027.

Luiselli L, Amori G. in press. Diet. In: Dodd Jr. CK, editor. Reptile ecology and conservation - a handbook of techniques. Oxford: Oxford University Press.

Luiselli L, Capula M, Shine R. 1996. Reproductive output, costs of reproduction, and ecology of the smooth snake, Coronella austriaca, in the eastern Italian Alps. Oecologia. 106:100-110.

Luiselli L, Capula M, Shine R. 1997. Food habits, growth rates, and reproductive biology of grass snakes, Natrix natrix (Colubridae) in the Italian Alps. J Zool. 241:371-380.

Luiselli L, Effah C, Angelici FM, Odegbune E, Inyang MA, Akani GC, Politano E. 2002. Female breeding frequency, clutch size, and dietary habits of a Nigerian population of Calabar ground python, Calabaria reinhardtii. Herpetological J. 12:127-129.

Maklakov AA, Simpson SJ, Zajitschek F, Hall MD, Dessmann J, Clissold F, Raubenheimer D, Bonduriansky R, Brooks RC. 2008. Sex-specific fitness effects of nutrient intake on reproduction and lifespan. Curr Biol. 18:1062-1066.

Petrozzi F, Eniang EA, Amadi N, Akani GC, Luiselli L. 2014. Temporal and spatial segregation in an assemblage of Afrotropical subterranean snakes. Amphibia-Reptilia. 35:345-353.

Pyron RA, Reynolds RG, Burbrink FT. 2014. A taxonomic revision of boas (Serpentes: boidae). Zootaxa. 3846:249-260.

Reading CJ, Luiselli L, Akani GC, Bonnet X, Amori G, Ballouard JM, Filippi E, Naulleau G, Pearson D, Rugiero L. 2010. Are snake populations in widespread decline? Biol Lett. 6:777-780.

Reynolds RG, Niemiler ML, Revell LJ. 2014. Toward a Tree-of-Life for the boas and pythons: multi locus species-level phylogeny with unprecedented taxon sampling. Mol Phyl Evol. 71:201-213.

Rodriguez-Robles JA, Bell CJ, Greene HW. 1999. Gape size and evolution of diet in snakes: feeding ecology of erycine boas. J Zool. 248:49-58.

Segniagbeto GH, Trape JF, David P, Ohler A, Dubois A, Glitho IA. 2011. The snake fauna of Togo: systematics, distribution and biogeography, with remarks on selected taxonomic problems. Zoosystema. 33:325-360.

Shine R. 1980. Ecology of the Australian death adder Acanthophis antarcticus (Elapidae): evidence for convergence with the Viperidae. Herpetologica. 36:281-289.

Shine R. 1989. Intersexual dietary divergence and the evolution of sexual dimorphism in snakes. Am Natur. 138:103-122.

Shine R, Slip DJ. 1990. Biological aspects of the adaptive radiation of Australasian pythons (Serpentes: Boidae). Herpetologica. 46:283-290.

Slip DJ, Shine R. 1988. Feeding habits of the diamond python, Morelia s. spilota: ambush predation by a boid snake. J Herpetol. 22:323-330.

Sorensen D. 1987. The genus Eryx. Bull Chicago Herp Soc. 23:21-25.

Tokar AA. 1995. Taxonomic revision of the genus Gongylophis Wagler 1830: G. conicus (Schneider 1801) and G. muelleri Boulenger 1892 (Serpentes Boidae). Trop Zool. 8:347-360.

Trape JF, Mane Y. 2006. Guide des serpents d'Afrique occidentale. Savane et désert. [Senegal, Gambia, Mauritania, Mali, Burkina Faso, Niger]. Paris: IRD Editions.

Trape JF, Trape S, Chirio L. 2012. Lézards, crocodiles et tortues dAfrique occidentale et du Sahara. Paris: IRD/ORSTOM.

Villiers A. 1950. La collection des serpents de I'IFAN. Dakar: IFAN Catalogues VI. 
Appendix 1. List of the localities of presence for Eryx muelleri.

\begin{tabular}{|c|c|c|}
\hline & Locality & Country \\
\hline ID & Original data & \\
\hline 1 & Mango & Togo \\
\hline 2 & Nanergou & Togo \\
\hline 3 & Borgou & Togo \\
\hline 4 & Kantchari & Burkina \\
\hline 5 & Tambaga & Burkina \\
\hline 6 & Korsimoro & Burkina \\
\hline 7 & Diabo & Burkina \\
\hline 8 & Bousse' & Burkina \\
\hline 9 & Laye (C. de Boussé) 23 Janv 1967 & Burkina \\
\hline 10 & Dijibasso 1969 & Burkina \\
\hline 11 & Gorom-Gorum (5/68) & Burkina \\
\hline 12 & Sampelga_Dori (année 1970) & Burkina \\
\hline 13 & Diébougou $(5 / 67)$ & Burkina \\
\hline 14 & Nouna $(12 / 69)$ & Burkina \\
\hline 15 & Bam $(6 / 67)$ & Burkina \\
\hline 16 & Fada N'gourma (3/68) & Burkina \\
\hline 17 & Kebbe & Nigeria \\
\hline 18 & Gummi & Nigeria \\
\hline 19 & Tambawel & Nigeria \\
\hline 20 & Sokoto & Nigeria \\
\hline 21 & Bunza & Nigeria \\
\hline ID & LITERATURE ENTRY & \\
\hline 22 & $16 \mathrm{Km} \mathrm{NW}$ of Niamey & Niger \\
\hline 23 & $30 \mathrm{~km}$ SE Niamey on road to Dosso & Niger \\
\hline 26 & $5 \mathrm{~km} \mathrm{~N}$ of Boussouma & Burkina \\
\hline 27 & 9 km NE of Hauts-Bassins: Barga & Burkina \\
\hline 24 & Segbana & Benin \\
\hline 30 & Dapango & Togo \\
\hline 29 & Hauts-Bassins: $9 \mathrm{~km}$ NE of Barga & Burkina \\
\hline 28 & Hauts-Bassins: 6 km SE of Seguenega & Burkina \\
\hline 25 & Haut Dahomey & Benin \\
\hline 30 & Ouagadougou & Burkina \\
\hline 31 & Diebougou & Burkina \\
\hline 33 & Near Maradi & Niger \\
\hline
\end{tabular}

